\title{
Introducing Pre-college Students and Teachers to Engineering Via a Summer Enrichment Program
}

\author{
Stephen Horan \\ New Mexico State University
}

\begin{abstract}
A week-long pre-college program for teachers and students has been developed to give the participants an introduction to engineering via hands-on activities. The program brings the students and teachers to campus where the construct two kits: a high-powered model rocket kit and a instrumentation package that is flown in the rocket. The program emphasizes problemsolving and critical thinking skills. Upon completion of the rocket flight, the data are analyzed using standard spreadsheets. The participants give oral presentations to describe the data collected, the interpretation of the data, and a description of their overall experience. The activities in the program have been tracked with the New Mexico secondary school curriculum standards to enable teachers to see how the material can be related to the various content areas. In this paper, the details of the program will be given along with sample reactions of the studentteacher teams participating in the program.
\end{abstract}

\section{Introduction}

Engineering faculty are always worried about filling the pipeline of new students coming into programs. Federal agencies such as the National Aeronautics and Space Administration (NASA) have developed extensive program support to assist in making outreach to pre-college customers part of the overall mission ${ }^{1}$. Through one of these programs, the New Mexico Space Grant Consortium, we have developed a one-week program that introduces high-school level teachers and students to engineering. The program has been running for over five years and services approximately 50 teachers and students every summer. Follow-up is also provided for the participating programs.

In this paper, we will describe the program and the kinds of technical and personal results obtained. We will also describe how this program has begun to feed back into the undergraduate curriculum at New Mexico State University.

\section{Program Operations}

The summer program recruits high-school level teachers and students from the state of New Mexico and west Texas to participate in a one-week, on-campus program. The program is funded through grants from NASA and corporate donations. Technology development support funding is also provided from within the Manuel Lujan Space Tele-Engineering program and the

"Proceedings of the 2001 American Society for Engineering Education Annual Conference \& Exposition Copyright (C) 2001, American Society for Engineering Education” 
Klipsch School of Electrical and Computer Engineering. The program is structured so that teachers and students apply as a team from their school. Multiple teams are allowed from each school and teachers are allowed to apply on subsequent years. Teachers are eligible to receive one credit hour of MS-level credit for participating. The program is designed to introduce the students to

1. Electronic construction techniques including soldering and circuit board assembly

2. Debugging and problem solving skills

3. Computer programming

4. Mathematical analysis and graphing using spreadsheets

5. Presentation skills.

These components are mapped to the New Mexico secondary school competencies ${ }^{2}$ to show the teachers how these concepts are useable in their classroom when implementing the components as part of their normal curriculum. Our mapping of the program to the competencies is one of the activities we conduct when the teachers are not involved with construction activities. This mapping activity generally proceeds as follows:

1. we step through each of the New Mexico competency areas, e.g. mathematics or science, and highlight the sup-topic areas in the 9-12 grade level that we believe we illustrate via some form of activity in during the program, e.g., "use manipulatives, calculators, computers, and other tools as appropriate in order to strengthen mathematical thinking" is fulfilled by the computer-based data analysis;

2. we explicitly show the mapping between the program guide and activities and the competency to the participating teachers and explain how we see the activity fulfilling all or part of the competency area;

3. we have an open discussion with the teachers about how they see the competency being fulfilled and we try to bring out related classroom activities at their grade level and subject that would also fulfill the competency.

The program is structured around two kits: a high-powered model rocket and an electronics package. The high-powered model rocket is a standard commercial kit that provides a 4-inch diameter, 8-inch long payload volume. The rocket in flight is illustrated in Figure 1. The electronic package was designed at New Mexico State University ${ }^{3}$ using commercial components and a circuit board designed by undergraduate students. The original design of the kit was developed during a one-semester senior-level design class. The kit includes

1. A microcontroller computer systems with a 10-channel analog-to-digital converter, BASIC interpreter, and memory.

2. Three accelerometers: two with 5-g sensitivity and one with 50-g sensitivity

3. Pressure measurement.

4. Photocell for roll measurements.

"Proceedings of the 2001 American Society for Engineering Education Annual Conference \& Exposition Copyright @ 2001, American Society for Engineering Education” 


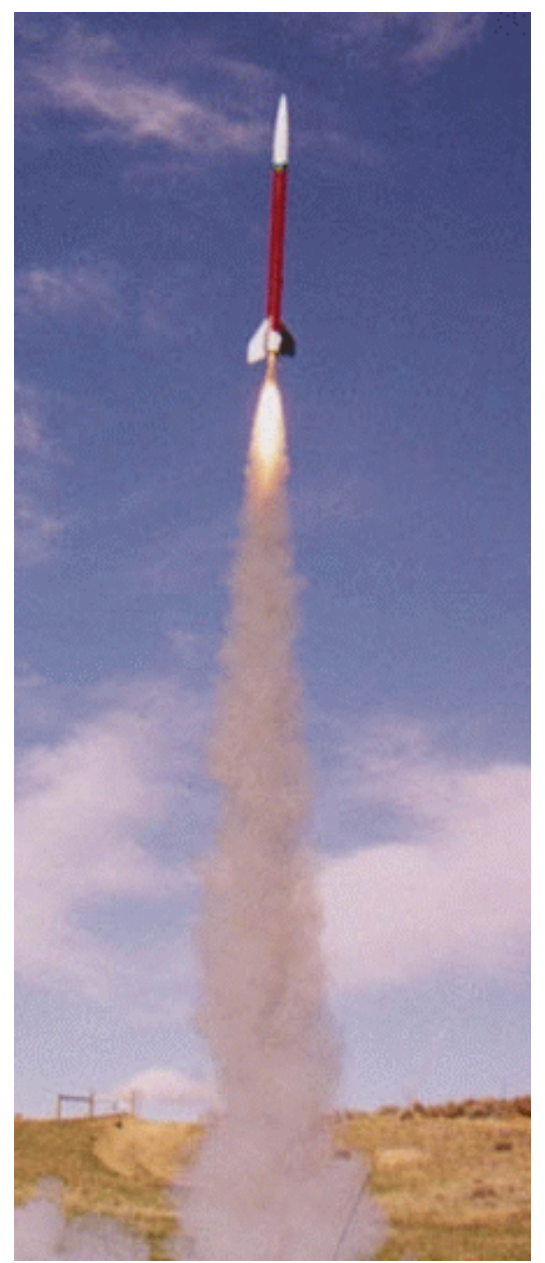

Figure 1 - Model rocket in flight.

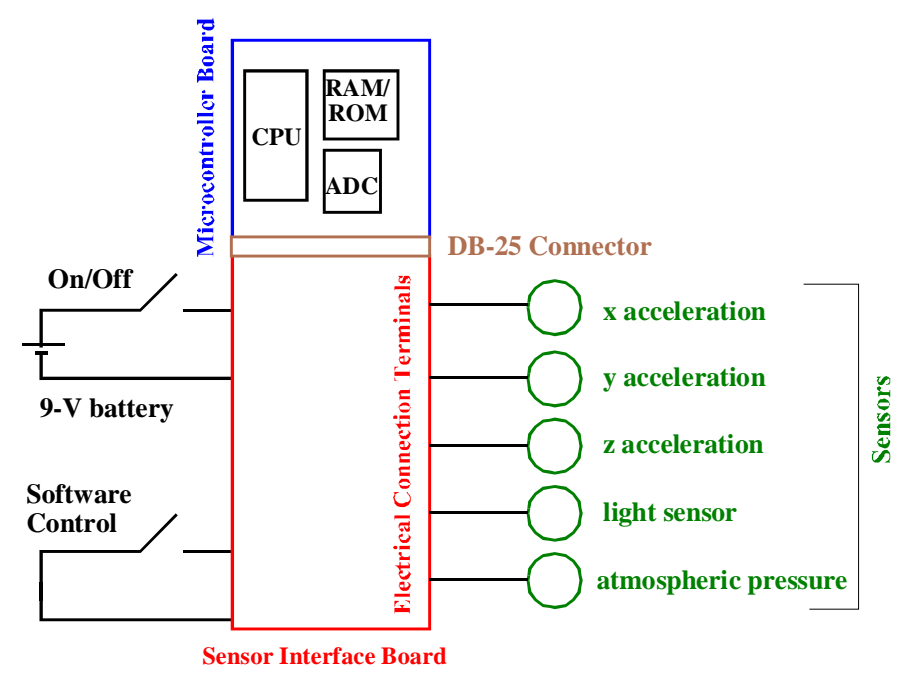

Figure 2 - Payload computer and sensor components

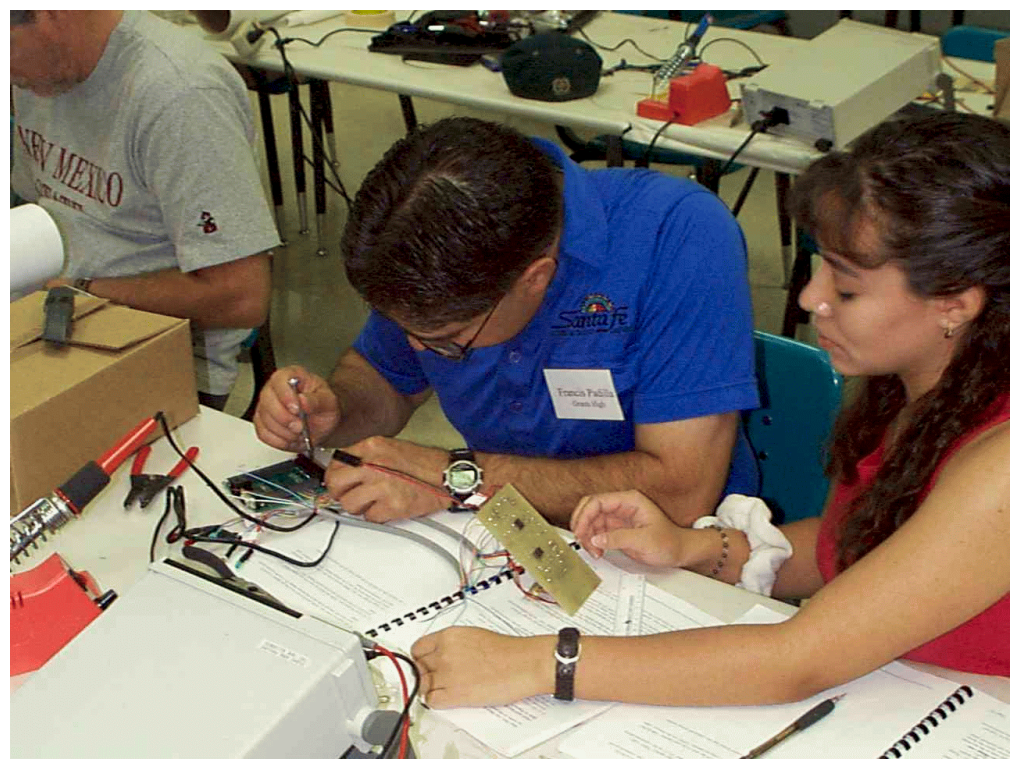

Figure 3 - A student-teacher team working on assembling the instrumentation package.

"Proceedings of the 2001 American Society for Engineering Education Annual Conference \& Exposition Copyright (C) 2001, American Society for Engineering Education” 


\begin{tabular}{|c|c|c|c|c|c|c|c|c|c|c|c|c|c|c|c|c|c|}
\hline time & data & Voltage & Pressure & height & rel height & & Voltage & & Voltage & Accel. & Rel Accel v & velocity & Height(m) & height(ft) & $x$-data & $x$-Voltage & $x$-accel \\
\hline 6.4 & 177 & 3.457031 & 873.7847 & 1320.805 & 0 & 7 & 0.136719 & 120 & 2.34375 & 1.171875 & 1.685578 & 0 & 0 & 0 & 131 & 2.558594 & 0.119579 \\
\hline 6.5 & 177 & 3.457031 & 873.7847 & 1320.805 & 0 & 7 & 0.136719 & 120 & 2.34375 & 1.171875 & 1.685578 & 0.168558 & 0.008428 & 0.027651 & 129 & 2.519531 & 0.03986 \\
\hline 6.6 & 176 & 3.4375 & 869.4444 & 1359.687 & 127.565 & 7 & 0.136719 & 119 & 2.324219 & 1.318359 & 3.12215 & 0.408944 & 0.037303 & 0.122385 & 130 & 2.539063 & 0.079719 \\
\hline 6.7 & 177 & 3.457031 & 873.7847 & 1320.805 & 0 & 7 & 0.136719 & 83 & 1.621094 & 6.591797 & 54.83875 & 3.306989 & 0.2231 & 0.731954 & 131 & 2.558594 & 0.119579 \\
\hline 6.8 & 177 & 3.457031 & 873.7847 & 1320.805 & 0 & 7 & 0.136719 & 43 & 0.839844 & 12.45117 & 112.3016 & 11.66401 & 0.97165 & 3.187827 & 118 & 2.304688 & -0.398597 \\
\hline 6.9 & 177 & 3.457031 & 873.7847 & 1320.805 & 0 & 7 & 0.136719 & 33 & 0.644531 & 13.91602 & 126.6674 & 23.61246 & 2.735473 & 8.974649 & 111 & 2.167969 & -0.677615 \\
\hline 7 & 177 & 3.457031 & 873.7847 & 1320.805 & 0 & 7 & 0.136719 & 34 & 0.664063 & 13.76953 & 125.2308 & 36.20737 & 5.726464 & 18.78761 & 132 & 2.578125 & 0.159439 \\
\hline 7.1 & 177 & 3.457031 & 873.7847 & 1320.805 & 0 & 7 & 0.136719 & 38 & 0.742188 & 13.18359 & 119.4845 & 48.44313 & 9.958989 & 32.67385 & 125 & 2.441406 & -0.119579 \\
\hline 7.2 & 177 & 3.457031 & 873.7847 & 1320.805 & 0 & 7 & 0.136719 & 40 & 0.78125 & 12.89063 & 116.6114 & 60.24793 & 15.39354 & 50.50375 & 131 & 2.558594 & 0.119579 \\
\hline 7.3 & 177 & 3.457031 & 873.7847 & 1320.805 & 0 & 7 & 0.136719 & 42 & 0.820313 & 12.59766 & 113.7382 & 71.7654 & 21.99421 & 72.15948 & 131 & 2.558594 & 0.119579 \\
\hline 7.4 & 177 & 3.457031 & 873.7847 & 1320.805 & 0 & 7 & 0.136719 & 44 & 0.859375 & 12.30469 & 110.8651 & 82.99557 & 29.73226 & 97.54678 & 126 & 2.460938 & -0.079719 \\
\hline 7.5 & 176 & 3.4375 & 869.4444 & 1359.687 & 127.565 & 6 & 0.11 & 45 & 0.878906 & 12.1582 & 109.4285 & 94.01025 & 38.58255 & 126.5832 & 132 & 2.578125 & 0.159439 \\
\hline 7.6 & 176 & 3.4375 & 869.4444 & 1359.687 & 127.565 & 3 & 0.058594 & 49 & 0.957031 & 11.57227 & 103.6822 & 104.6658 & 48.51635 & 159.1744 & 129 & 2.519531 & 0.03986 \\
\hline 7.7 & 176 & 3.4375 & 869.4444 & 1359.687 & 127.565 & 2 & 0.039063 & 53 & 1.035156 & 10.98633 & 97.93592 & 114.7467 & 59.48697 & 195.1672 & 131 & 2.558594 & 0.119579 \\
\hline 7.8 & 176 & 3.4375 & 869.4444 & 1359.687 & 127.565 & 2 & 0.039063 & 57 & 1.113281 & 10.40039 & 92.18963 & 124.253 & 71.43696 & 234.3732 & 125 & 2.441406 & -0.119579 \\
\hline 7.9 & 176 & 3.4375 & 869.4444 & 1359.687 & 127.565 & 2 & 0.039063 & 61 & 1.191406 & 9.814453 & 86.44334 & 133.1846 & 84.30883 & 276.6038 & 133 & 2.597656 & 0.199298 \\
\hline 8 & 176 & 3.4375 & 869.4444 & 1359.687 & 127.565 & 2 & 0.039063 & 66 & 1.289063 & 9.082031 & 79.26048 & 141.4698 & 98.04156 & 321.6587 & 120 & 2.34375 & -0.318878 \\
\hline 8.1 & 176 & 3.4375 & 869.4444 & 1359.687 & 127.565 & 2 & 0.039063 & 75 & 1.464844 & 7.763672 & 66.33133 & 148.7494 & 112.5525 & 369.2668 & 127 & 2.480469 & -0.03986 \\
\hline 8.2 & 176 & 3.4375 & 869.4444 & 1359.687 & 127.565 & 3 & 0.058594 & 85 & 1.660156 & 6.298828 & 51.96561 & 154.6642 & 127.7232 & 419.0394 & 129 & 2.519531 & 0.03986 \\
\hline 8.3 & 176 & 3.4375 & 869.4444 & 1359.687 & 127.565 & 7 & 0.13 & 92 & 1.796875 & 5.273438 & 41.9096 & 159.358 & 143.4243 & 470.5522 & 128 & 2.5 & \\
\hline 8.4 & 175 & 3.417969 & 865.1042 & 1398.763 & 255.7684 & 7 & 0.136719 & 98 & 1.914063 & 4.394531 & 33.29017 & 163.118 & 159.5481 & 523.4518 & 129 & 2.519531 & 0.03986 \\
\hline 8.5 & 175 & 3.417969 & 865.1042 & 1398.763 & 255.7684 & 7 & 0.136719 & 108 & 2.109375 & 2.929688 & 18.92445 & 165.7287 & 175.9904 & 577.3965 & 129 & 2.519531 & 0.03986 \\
\hline 8.6 & 175 & 3.417969 & 865.1042 & 1398.763 & 255.7684 & 7 & 0.136719 & 127 & 2.480469 & 0.146484 & -8.370428 & 166.2564 & 192.5897 & 631.856 & 134 & 2.617188 & 0.239158 \\
\hline 8.7 & 174 & 3.398438 & 860.7639 & 1438.036 & 384.6167 & 7 & 0.136719 & 137 & 2.675781 & -1.318359 & -22.73615 & 164.7011 & 209.1376 & 686.1469 & 128 & 2.5 & \\
\hline 8.8 & 174 & 3.398438 & 860.7639 & 1438.036 & 384.6167 & 7 & & 145 & 2.832031 & -2.490234 & -34.22873 & 161.8529 & 225.4653 & 739.7155 & 128 & 2.5 & \\
\hline 8.9 & 173 & 3.378906 & 856.4236 & 1477.508 & 514.1163 & 7 & 0.136719 & 143 & 2.792969 & -2.197266 & -31.35558 & 158.5736 & 241.4866 & 792.2789 & 130 & 2.539063 & 0.079719 \\
\hline 9 & 173 & 3.378906 & 856.4236 & 1477.508 & 514.1163 & 7 & 0.136719 & 143 & 2.792969 & -2.197266 & -31.35558 & 155.4381 & 257.1872 & 843.79 & 130 & 2.539063 & 0.079719 \\
\hline 9.1 & 173 & 3.378906 & 856.4236 & 1477.508 & 514.1163 & 4 & 0.078125 & 142 & 2.773438 & -2.050781 & -29.91901 & 152.3743 & 272.5778 & 894.2842 & 128 & 2.5 & \\
\hline 9.2 & 172 & 3.359375 & 852.0833 & 1517.18 & 644.2738 & 2 & 0.039063 & 142 & 2.773438 & -2.050781 & -29.91901 & 149.3824 & 287.6656 & 943.785 & 130 & 2.539063 & 0.079719 \\
\hline
\end{tabular}

Figure 4 - Spreadsheet showing relative time, raw sensor values, converted measurements, and derived measurements.

"Proceedings of the 2001 American Society for Engineering Education Annual Conference \&

Exposition Copyright $\odot$ 2001, American Society for Engineering Education" 
The configuration of the electronic payload is illustrated in Figure 2. The student-teacher teams are provided with an instruction manual ${ }^{4}$ for assembling the kits, guidance in soldering, and assistance in debugging the assembled board. A typical team working on the kit is shown in Figure 3. Prior to flight, all teams perform a "test flight" run to ensure that all components are working correctly and that the computer acquires the data.

After the flight, each team's data is downloaded from the flight computer and the data is converted from raw ADC output to unit-based measurements. A typical spreadsheet for such an analysis is illustrated in Figure 4. The teams are given instruction on how to convert the measurements from ADC output to unit-based measurements by showing the sampling process for each sensor and the manufacturer's calibration for the sensor. Additional derived parameters that can be obtained from the data are

1. Relative height determined by using a model atmosphere to convert pressure reading to height

2. Velocity in the vertical direction based upon numerically integrating the acceleration

3. Height in the vertical direction based upon numerically integrating the velocity.

These derived parameters are developed to expand the instruction into mathematics and atmospheric measurements. Throughout the program, there is a constant dialog between the program staff and the teachers on how the measurements, computers, and analysis techniques can be used in their curriculum and how other subject areas can be brought in.

\section{Results}

There are two types of results found in a project like this: the technical success of the measurement system and the experience of the students and teachers. The technical success is easier to quantify. The experiential success is more anecdotal but valuable nonetheless.

The technical success is measure by having each group produce a set of reduced data from the flight. This includes

1. Measurements converted from raw sensor readings to useable data in proper units using the spreadsheet analysis techniques.

2. Developing time-series plots of the converted data using the spreadsheet analysis

3. Being able to explain the meaning of the data and what is happening in the flight profile as expressed in the data. This is done at a group presentation on the final day of the program.

A typical set of plots is given in Figures 5 and 6 where data from one of the student payloads is illustrated.

The experience is usually very intense for the students because there is a lot of work to be

"Proceedings of the 2001 American Society for Engineering Education Annual Conference \& Exposition Copyright $\odot$ 2001, American Society for Engineering Education" 

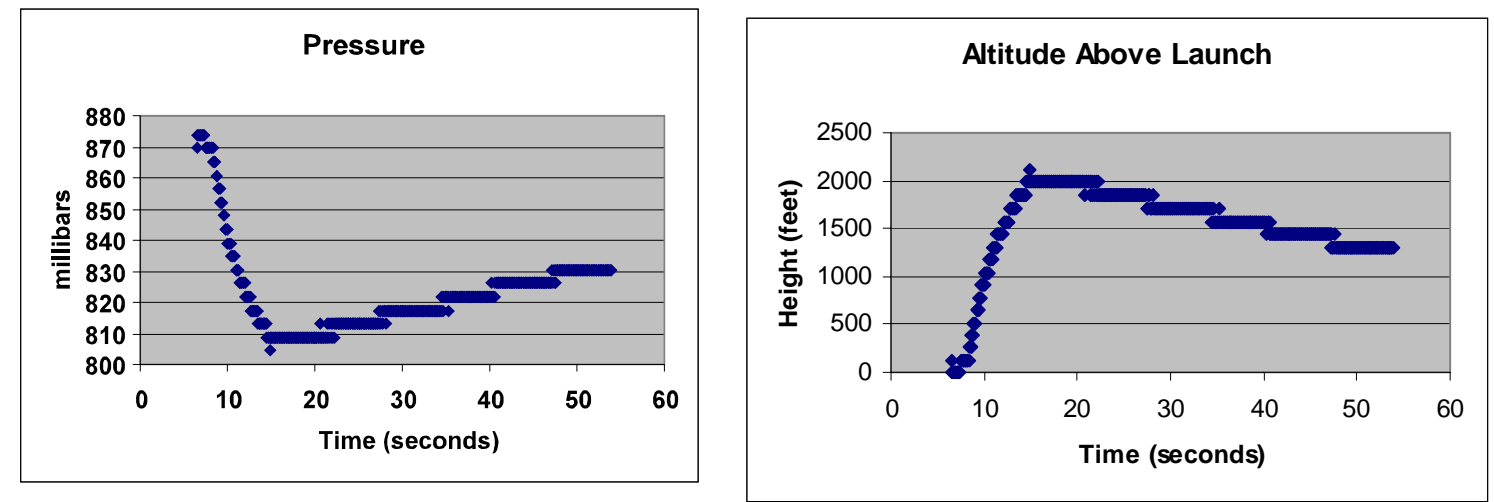

Figure 5 - Pressure measurement and corresponding relative height measurement.
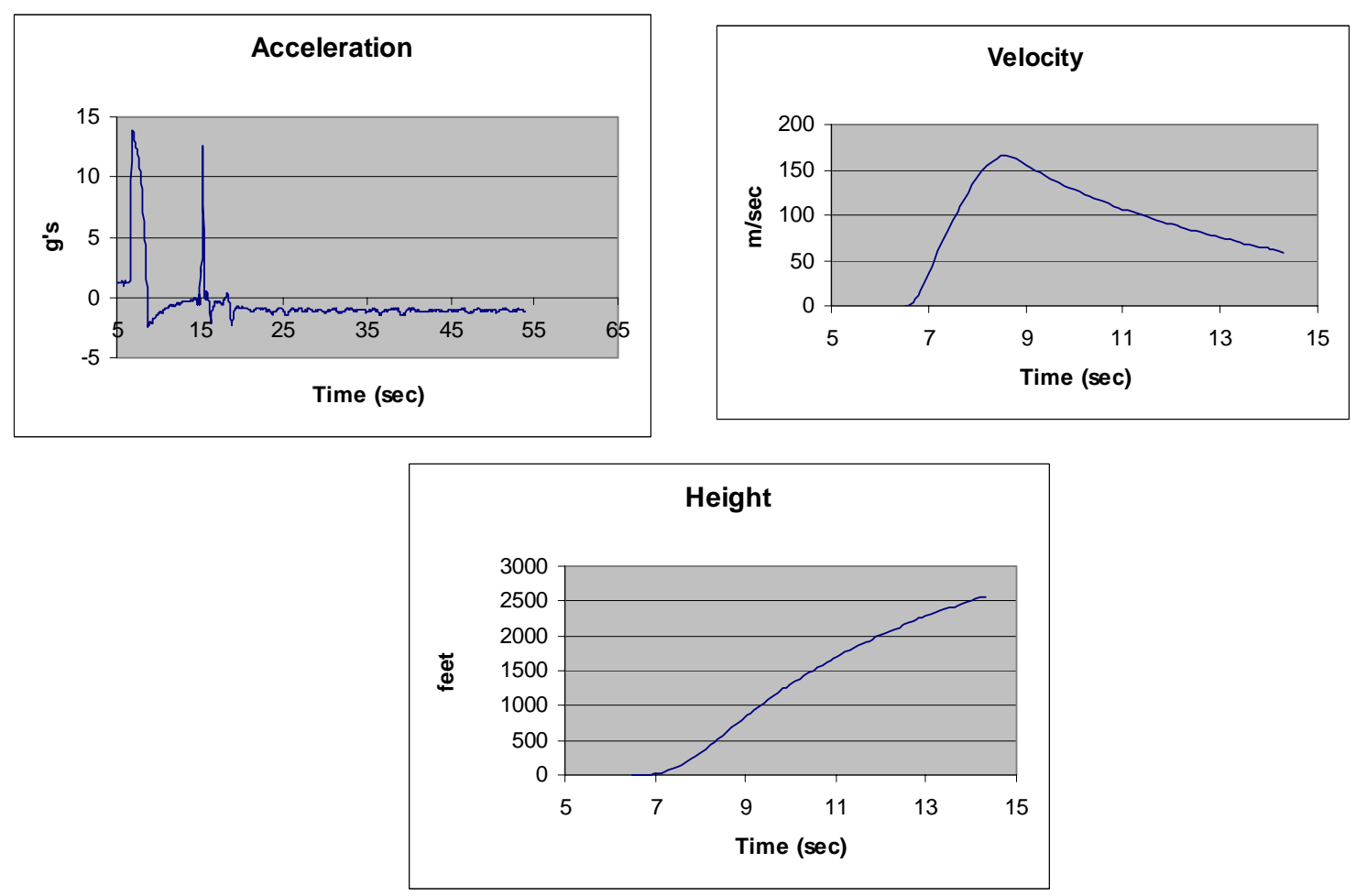

Figure 6 - Vertical acceleration measurement and derived velocity and height estimates.

"Proceedings of the 2001 American Society for Engineering Education Annual Conference \& Exposition Copyright (C) 2001, American Society for Engineering Education” 
accomplished in one week. Several years ago, one student indicating that she now knew that engineering will not be her field but she was glad for the experience to find out. Typical comments from students and teachers participating in the 2000 summer program were ${ }^{5}$ :

1. It has been a fun and educational week. I plan to explore other job opportunities in engineering.

2. Learned! Had a blast!

3. We had a new and wonderful experience. We had fun, made a few friends, and experienced something we built work.

4. To all the participants in this program ... hope that you take this info back to your school for everyone to see.

5. Open my mind to a new career in engineering. Learned new and interesting things. Found out that a lot of failure goes into creating new things.

Given that we have returning teacher applicants each year, we take that as an indication that the program is reaching the target audience and helping the teachers in their mission.

The program also interacts with the regular undergraduate curriculum in the electrical engineering program. The payload started as a senior-level design class to select the sensors and the microcontroller computer system, verify the basic design and form factor for the model rocket. Subsequently, engineering students have been involved with designing improvements to the payload and the circuit board to hold the electronics. The faculty in the circuits and electronics classes are now looking to use the various types of sensors as the basis for laboratory experiments in the introductory classes so that the students have physical measurements to use as the basis for the experiment. For example, instead of using a waveform generator as the input signal to an amplifier circuit, they are using the output of an uncompensated pressure sensor to be the source for the measurement. This way, the students are seeing that the electronics techniques have application to the external world.

\section{Summary}

In this paper we present a unique summer program for high school level teachers and students to introduce them to engineering concepts. The program is tied to state secondary school competencies for mathematics and science. Anecdotal evidence shows that the students have a better understanding of engineering as a subject and a career. Some of the sensors used in the program are also being fed back to the NMSU undergraduate curriculum as appropriate electronics to be used in the laboratories.

\section{Bibliography}

1. National Aeronautics and Space Administration, "The NASA Education Program and Evaluation Framework" URL: http://education.nasa.gov/implan/framewrk.html.

\footnotetext{
"Proceedings of the 2001 American Society for Engineering Education Annual Conference \&
} Exposition Copyright (C) 2001, American Society for Engineering Education” 
2. Center for the Education and Study of Diverse Populations, "New Mexico Content Standards and Benchmarks Reference Guide," URL: http://www.cesdp.nmhu.edu/standards/download/index.htm

3. S. Horan, "Use of High-Power Model Rockets as a Laboratory for a Microcontroller Data Acquisition System," A.S.E.E. Computers in Education, Vol. VI, No. 1, January-March 1996, p. 53-56.

4. New Mexico Space Grant Consortium, “Student Launch Project - Summer Institute,” July 2000.

5. URL: http://spacegrant.nmsu.edu/Summer00/index.htm

\section{STEPHEN HORAN}

Stephen Horan holds the Frank Carden Chair in Telemetering and Telecommunications in the Klipsch School of Electrical and Computer Engineering at New Mexico State University. Dr. Horan received an A.B. in Physics from Franklin and Marshall College in 1976, and M.S. in Astronomy in 1979 and a Ph.D. in Electrical Engineering in 1984 from New Mexico State University.

"Proceedings of the 2001 American Society for Engineering Education Annual Conference \& Exposition Copyright (C) 2001, American Society for Engineering Education” 